NBER WORKING PAPER SERIES

\title{
GENERIC ENTRY AND THE PRICING \\ OF PHARMACEUTICALS
}

Richard G. Frank

David S. Salkever

Working Paper 5306

\author{
NATIONAL BUREAU OF ECONOMIC RESEARCH \\ 1050 Massachusetts Avenue \\ Cambridge, MA 02138 \\ October 1995
}

The authors are grateful to Ernie Berndt and Judy Wagner for providing data and advice for this analysis. Marissa Domino provided expert research assistance. Dr. Albert Wu assisted us in classifying clinical conditions and we thank him for that help. Useful comments were received from Zvi Griliches, Alison Keith, Alan Garber and participants in seminars at the NBER Summer Institute, the 2nd D.V.A. Industrial Organization and Health Conference, the NBER Productivity workshop, the Department of Statistics and the Department of Health Care Policy at Harvard University. This paper is part of NBER's research program in Health Care. Any opinions expressed are those of the authors and not those of the National Bureau of Economic Research.

(C) 1995 by Richard G. Frank and David S. Salkever. All rights reserved. Short sections of text, not to exceed two paragraphs, may be quoted without explicit permission provided that full credit, including $(\mathcal{O}$ notice, is given to the source. 


\title{
GENERIC ENTRY AND THE PRICING \\ OF PHARMACEUTICALS
}

\begin{abstract}
During the 1980s the share of prescriptions sold by retail pharmacies that was accounted for by generic products roughly doubled. The price response to generic entry of brand-name products has been a source of controversy. In this paper we estimate models of price responses to generic entry in the market for brand-name and generic drugs. We study a sample of 32 drugs that lost patent protection during the early to mid-1980s. Our results provide strong evidence that brand-name prices increase after entry and are accompanied by large price decreases in the price of generic drugs.
\end{abstract}

Richard G. Frank

Department of Health Care Policy

Harvard Medical School

Parcel B, 1st Floor

25 Shattuck Street

Boston, MA 02115

and NBER
David S. Salkever

Department of Health Policy \& Management

School of Hygiene and Public Health

Room 429 - Hampton House

The Johns Hopkins University

624 North Broadway

Baltimore, MD 21205

and NBER 


\section{Introduction}

Since the passage of the Waxman-Hatch Act in 1984 there has been a dramatic increase in entry of generic drugs into markets for pharmaceutical products. The Waxman-Hatch Act eased the testing requirements for entry by generic drugs. This legislation accompanied by the expiration of patents on a large number of high sales volume brand-name drugs is altering the competitive dynamics of pharmaceutical market place. During the. 1980 s the share of prescriptions sold by retail pharmacies that were accounted for by generics roughly doubled. The price response of brand-name drugs was surprising and remains controversial (OTA, 1993). Prices for drugs were observed to rise in response to generic entry (see for example Grabowski and Vernon 1992). At the same time these conclusions were questioned by recent empirical analyses (Wiggins and Maness 1994). In their analysis of the market for anti-infective drugs they found a response to entry that is consistent with the predictions of traditional market models; pioneer (or brand-name) price declines as entry expands. In this paper we estimate models of price responses to generic entry in the markets for generics and brand-name drugs for a broad sample of drugs that lost patent protection between the years 1983 and 1987.

The price models estimated below examine the experiences of 32 drugs that lost patent protection during the mid 1980s. We make use of information on transactions prices paid by retail pharmacies. All the drugs studied experienced significant entry by generics during the first years off patent. Our results provide strong evidence that brand name prices increase after 
entry but are accompanied by large decreases in the price of generic products. The net effect is a reduction in the average price of a prescription for an off patent drug.

The paper is organized into 5 sections. The second section takes up some theoretical considerations for the empirical model of prices and examines existing evidence on price responses to entry from the literature. The empirical implementation of the pricing models are describedin the third section. The fourth section presents estimation results. A discussion of the implications of the findings appears in the fifth and final section of the paper.

\section{Background}

\section{A. Theoretical Considerations}

The theoretical point of departure for the empirical models estimated below is the model of Frank and Salkever (1992). Their model was developed to explain the positive correlation between generic entry and brand-name price levels. In that analysis the demand side of the market for a particular drug is conceived as consisting of two major segments, one that is price insensitive and a second that is price responsive. The price insensitive component might consist of the patients of physicians in fee for service practice, while the insensitive component would consist of prescriptions filled on behalf of enrollees in HMOs and patients in hospitals. Entry of generics leads price sensitive buyers to shift to generics, leaving only price insensitive buyers to purchase brand-name products. This causes the brandname producers' demand function to shift inward and to become less elastic, allowing the profit maximizing brand-name firm to 
raise its price.

The model posits that brand-name drug manufacturers behave as von stackelberg price leaders. That is, a brand-name drug producer is a dominant firm that makes its profit maximizing pricing decisions taking account of the reaction to its pricing choices in the generic market. Producers of generic versions of brand-name products are viewed as fringe firms playing a NashCournot non-cooperative game. Each firm takes the brand-name. producer's price and the behavior of rival generic producers as given in making its profit maximizing pricing decision. The implications of this model for empirical analyses are several:

a) The price equation for generic product price can be written as:

(1) $P_{g}^{*}=P_{g} *\left(n, P_{b}\right)$

where $P_{g}$ * is the equilibrium price of a generic product, $n$ is the number of generic producers, and $P_{b}$ is the brand-name producer's price.

b) The price equation for brand-name price can be written as :

(2) $P_{b}=P_{b}(n, w)$

where $w$ is a vector in input prices. The reduced form brand-name price equation suggests that generic entry affects price through the effect of generic price on brand-name demand. Frank and Salkever (1992) show that $\mathrm{dP}_{b} / d n<0$ unless entry increases brandname demand, marginal costs are decreasing or entry makes the demand curve less elastic (steeper). There is little support for the first two conditions in the empirical literature (OTA, 1993, Comanor 1986 and Scherer 1993). Thus we posit that a positive partial correlation between $n$ and $P_{b}$ would primarily reflect the 
impact of generic entry on the brand-name demand curve.

\section{B. Evidence from the Literature}

Three recent empirical analyses have estimated the relationship $\mathrm{dP}_{\mathrm{b}} / \mathrm{dn}$ and have arrived at substantially different conclusions. Grabowski and Vernon (1992) examined the effect of generic entry on prices for 18 high sales-volume pharmaceutical products that were first exposed to generic competition during : the years 1983 through 1987. For each drug the authors examined prices prior to entry and prices 1 year following generic entry. Grabowski and Vernon (1992) specified regression models that had as the dependent variable the ratio of generic to brand-name price and three independent variables: 1) the number of generic product sellers, 2) the total dollar of sales in the market for the chemical and 3) a time dummy variable. The estimated coefficient for the impact of the number of generics on the ratio of generic to brand-name price was negative and significantly different from zero. This result is consistent with the descriptive information reported by Grabowski and Vernon (1992) showing brand-name price rising relative to generic prices subsequent to generic entry.

Caves, Whinston and Hurwitz (1991) are concerned that simple pre-post entry brand-name price comparisons or simple regression of price on number of generic entrants may lead to underestimates of the downward impact on prices that generic entry may really have. They suggest that other omitted factors may have caused brand-name prices to rise overtime. Specifically they argue that after 1982 the producer price index (PPI) for pharmaceutical rose 
sharply relative to indices of labor and material costs. 1 The authors therefore take great pains to minimize the effect from unobservable time-varying factors which might be responsible for the types of results reported by Grabowski and Vernon (1992).

Caves, Whinston and Hurwitz (1991) studied the experience of 30 drugs that went off patent between 1976 and 1987. These drugs studied represent all drugs in therapeutic classes where "important" drugs lost their patent protectioni In the regression models of brand-name prices, reported by Caves, Whinston and Hurwitz (1991), more than 50 individual intercepts were included to account for each of the year-therapeutic category combinations in their data. The regression results therefore represent an analysis of deviations in individual drug prices from the therapeutic category-year group average changes in each year. The regression model also included time related dummy variables, a linear time trend and a quadratic time trend in order to capture discontinuities in price behavior around the time of patent expiration.

The measure of generic entry used in the model was the number of Amended New Drug Applications for marketing of a new chemical entity, actual entry was not directly measured. In some specifications entry was treated as endogenous. The estimated regressions found that initial entry by generic products led to reductions in brand-name price of about $2 \%$. Entry by 20 generics

1 Berndt, Griliches and Rosett (1990) point out that the PPI was substantially biased in an upward direction. They argue that the reason for this bias is there were important differences in the drugs included in the PPI sample and the universe of pharmaceutical products. 
results in price decreases of $17 \%$. These were viewed as very small price responses to entry. The responses were somewhat larger in markets where hospital share of sales were larger. Caves, Whinston and Hurwitz (1991) also estimate a regression model that was quite similar to the one estimated by Grabowski and Vernon (1992) and obtained very similar results. In view of the enormous complexity of the models estimated by Caves, Whinston and Hurwitz (1991) it would besimportant to uriderstand the sensitivity of their results to the specific model chosen by the authors.

Wiggins and Maness (1994) have recently studied price competition in the market for anti-infectives over the period 1984 to 1990. The anti-infectives studied include 98 compounds. Some of the drugs studied had been off-patent for many years (e.g. penicillin), while others more recently became prone to generic competition. Following Caves, Whinston and Hurwitz (1991), Wiggins and Maness include a number of fixed effects to control for unobserved factors that might influence price. The specific fixed effects specified include one set for type of anti-infective, a second set indicated if the product was introduced in a given year, and the third set was a vector of year specific dummy variables. The specification used for estimating the model of pioneer brand prices reflected a cournot formulation and allowed for a non-linear impact of exogenous entry.

The model was estimated using data on brand-name prices only. The estimated coefficients showed that market entry by generics results in significant reductions in the price of antiinfective products. The entry by other brand-name products was 
estimated to lower price but was significant only at the $10 \%$ level. Descriptive information reported by Wiggins and Maness (1994) suggests that there are three observations in the data where there are few (or zero) entrants accompanied by high prices (Panel C, Figure 2). They speculate as to why their results differ from other studies; they offer sample size and use of fixed effects as two explanations. They also suggest, as do other students of the pharmaceutical industry, that antiinfectives have followed a different pattern from the larger universe of pharmaceutical products (Scherer 1993 OTA, 1993). It is therefore, important to use a large sample with careful attention to unmeasured factors to determine the extent to which analyses based solely on data from the anti-infective market generalizes to the industry.

\section{Empirical Implementation}

The empirical analysis of pharmaceutical pricing reported below estimates parameters for models of both brand-name and generic products. These empirical models correspond to equations (1) and (2) discussed above. The unit of observation in these models is either the brand-name compound-year or the generic compound-year. We make use of a data set that consists of drugs that first faced competition during the period 1984-1987. The econometric models estimated include both single equation models where the number of competitors is treated as exogenous (such as in the work of Grabowski and Vernon 1992, and Wiggins and Maness 1994) and two-stage least squares models where the number of competitors is endogenous. 


\section{A. Data}

Between 1984 and 198783 compounds faced generic competition for the first time. All these drugs lost patent protection between 1979 and 1987. From this group of products, drugs were eliminated if a) they became over the counter products which no longer required a prescription for purchase (e.g. ibuprofen), b) they were combination products, or c) were not sold to drug stores in quantity (these include injectibles and infusibles which account for a very small part of the outpatient market). After applying the above exclusion criteria 45 drugs remained in the sample. ${ }^{2}$

Several of the drugs reported zero sales during the $1980 \mathrm{~s}$ and were thus eliminated from the data base, reducing the sample to 41 compounds. Antibiotics were eliminated from the sample due to the complicated licensing arrangements that exist in this area which made defining entry and patent loss hazardous. The resulting sample of drugs for analysis was $32 .^{3}$

Information on dollar sales volume, unit sales volume and generic market share were obtained from IMS America Inc. MIDAS system using the United States Drugstore and Hospital data base for the years 1980 through 1991. According to IMS, in 1986 these

${ }^{2}$ The data on volume and prices of drugs were originally collected by stephen Schondelmeyer on behalf of the U.S. Office of Technology Assessment. We are grateful to Judy Wagner for making these data available to us.

${ }^{3}$ The drugs included in the analysis had average sales of $\$ 80$ million in the year prior to patent loss. 
data covered $98 \%$ of pharmaceutical sales in the U.S. Data on years for which a name-brand was sold prior to patent loss, market entry date for generics, number of non-originator firms, and whether drugs are used primarily to treat chronic, acute or sub-acute conditions were added to the IMS data set. The definitions of key variables and their data sources are listed on Table 1. All data were aggregated to the year level from quarterly reports of sales.

The main dependent variablẹs in the analyses reported here are the average transactions revenue per extended unit of a drug. An extended unit is defined as the most basic unit measure of volume for a given product such as a capsule or a gram for drugs sold by weight. The extended unit varies by product. Thus, the dependent variable is the manufacturer dollar sales based on transactions data divided by the number of extended units. ${ }^{4}$ For generics the dependent variable is the sum of generic sales (across producers) divided by the sum of extended units sold. The main right hand side variable of interest in this analysis is the number of generic sellers in the market (NMFT). This variable was constructed by using information from the USP DI (or Orange Book) for 1987,1990 and 1991. The NMFT variable counts the number of non-originator drug sellers in the market in each year post patent expiration.

${ }^{4}$ All dollar sales figures were deflated by the CPI All-Items Index . 


\section{B. Estimation}

In order to estimate the impact of generic entry on market prices three sets of models were estimated for the prices of brand-name and generic drugs. We first estimate single equation fixed effects models where NMFT is treated as exogenous. ${ }^{5}$ In this model we make use of time and compound specific fixed effects to control for unobserved secular trends (e.g. input prices) and time invariant (compound specific) unobservables: The second specification relaxes the assumption that NMFT is exogenous. Following Caves, Whinston and Hurwitz (1991) use the amount of time off patent as one instrument. A two stage least squares fixed effect estimator is used for this model.

The third model also makes use of a two-stage estimator. In this specification we include an indicator of demand for overall demand for a compound and the age of the market as well as the time off patent as an instrument in the first stage. The demand is measured as the sales in the year prior to patent expiration. The age of the market is a second instrument; it is viewed as an indicator of entry friction stemming from loyalty to the originator brand and habit by physicians in their prescribing patterns. Since these two variables are time invariant we used a variance component estimator instead of the fixed effects model. In the second stage a fixed effects estimator is used. ${ }^{6}$ The

${ }^{5}$ Of particular concern are trends in shifting market composition. That is enrollment in managed care plans grew during the period. The time fixed effects were introduced to account for these trends.

${ }^{6}$ It is worth noting that we estimate two versions of the first stage variance components model. 
Hausman test led to a rejection of the consistency of the variance components estimator in the second stage in all specifications.

\section{Results}

\section{A. Descriptive Findings}

Figure 1 shows the behavior of brand-name prices subsequent to market entry by generic producers. The vertical axis measures the current brand-name pricerelative to the pre-patent price. The horizontal axis measures the time, in years, since the initial entry into the market by generics. Note that the data suggest an upward drift in real brand-name prices. These data are consistent with the observations made by Grabowski and Vernon (1992). The Figure shows that shows a 50\% rise in brand-name price five years post generic entry. The trend runs counter to the notion that brand-name producers engage in vigorous price competition with generic entrants. Figure 2 offers a analogous view of the behavior of generic prices during the period following initial market penetration. Note that three years after generic entry generic prices are less than $50 \%$ of the brand-name price. These data are supportive of the view that the generic market represents a highly competitive fringe to the brand-name drug market.

Figure 3 presents information on the behavior of generic prices relative to brand-name prices as the number of firms selling a compound increases. The graph in Figure 3 suggests that expanded entry is consistent with a downward drift in the ratio of generic to brand-name price. The relationship is not monotonic as was observed in the time path of prices. This indicates that the timing of entry by generics does not occur continuously 
overtime. Figure 4 shows the number of generic entrants in relation to the years since patent protection was lost. The graph reflects the fact that on average about five generic producers enter a market during the first post-patent year of the brandname product. During the subsequent three years entry is considerably slower with three additional generic producers entering on average. These data are consistent with robust competition in the market for generic products.

\section{B. Econometric Estimates}

In this section we present the results from our econometric models of pharmaceutical prices. We begin by examining the estimates for our model of the number of generic entrants into the market for specific compounds subsequent to loss of patent protection. Table 2 reports one fixed effect and two variance components regressions for the number of generic entrants (NMFT). The first column reports the fixed effect estimates. The likelihood ratio tests indicates that both the time and compound specific fixed effects are significantly different from zero (240.69 and 338.62 respectively). The coefficient estimate for the Yrs off variable is significantly different from zero. The magnitude of the coefficient implies that for each year postpatent protect there is about one additional entrant into the market for a particular drug.

The variance components regressions are presented in the second and third columns of Table 2. Two specifications are presented, with and without a linear time trend. The pre-patent loss brand name level of sales of the drug is included as a proxy for the overall demand for the compound. The results reported in 
the second column suggest that the pre-patent loss sales have a significant positive impact on subsequent generic entry. The estimated elasticity evaluated at the mean of sales and number of entrants is 0.47 , indicating that a $10 \%$ difference in pre-patent loss sales result in $4.7 \%$ more entrants post-patent. The number of years for which the brand-name drug was sold had no significant impact on entry. ${ }^{7}$ Thus the brand name selling period does not seem to be the source of friction for entry by generics. The measure of years off patent. shows that for each year post patent there is on average one new entrant.

The results reported in the third column are qualitatively similar. The estimated coefficient for years off patent varies across the models from 0.734 to 1.45 . The fixed effects result lies between the other two specifications. The rather strong estimates for the time trend effect in Table 2 suggest that the entry process has become substantially easier over the time period studied. This is consistent with the objectives of the Waxman-Hatch Act.

Table 3 reports the estimates for the brand-name price regressions. Recall that these estimates are all based on fixed effects models that include separate intercepts for each compound and each year. The first column of Table 3 reports regression results for a model where the number of generic competitors is assumed to be exogenous. Unobserved factors that affect both entry and brand-name price are posited to be accounted for by the fixed effects. In that model the impact on brand-name price of a

${ }^{7}$ Recall that this variable is time invariant so that it is excluded from the 1st stage fixed effects model. 
change in the number of competitors $\mathrm{dP}_{b} / \mathrm{dn}$ is estimated to be positive and significant at conventional levels (0.05). The parameter estimate suggests that each new entrant will result in roughly a $0.7 \%$ increase in the brand name price.

The estimated models reported in the second and third columns of Table 3 each treat the number of competitors as endogenous. The model in the second column uses a first stage model that corresponds to the first column of Table 2. The third column uses a first stáge model that corresponds to the second column of Table 2 . The results for the two stage models indicate stability in the coefficient estimates for the number of competitors. The estimates for both two stage models of the impact of generic entry are significantly different from zero at conventional levels. The range of the estimates is quite small $(0.007$ to 0.016$)$. It should be noted that the 0.007 and the 0.016 estimates are significantly different from one another at close to the 0.05 level. The evidence is therefore consistent with the view that generic entry drives brand-name prices up. ${ }^{8}$

Table 4 reports two stage fixed effects generic price regression results. All three specifications treat the number of competitors as endogenous. The coefficient estimates for the NMFTHAT variable are quite consistent across the three specifications. In all cases the coefficient estimates are

8 We also examined the possibility that drugs used regularly for chronic conditions may display different price dynamics. We therefore interacted a dummy variable representing chronic use with the level of generic competition in our pricing models. In all cases we failed to reject the hypothesis that drugs used for different types of illnesses had different price responses to competition. 
negative and significantly different from zero at conventional levels. The parameter estimates indicate that each additional entrant reduces the average price of a generic product by between $5.6 \%$ and $7.2 \%$. Thus moving from the sample mean of about 3 competitors to 6 competitors would reduce prices by between $17 \%$ and $22 \%$. The coefficient estimate for the brand-name price was estimated to be consistently positive but was never significantly different from zero. 9 This is probably due to the fact that the between compound variation in brand name price is considerably greater than the within variation. Thus, the inclusion of compound specific fixed effects may lead to the imprecision in the coefficient estimate for the brand-name price variable. ${ }^{10}$

\section{Implications and Conclusions}

Pricing in the pharmaceutical industry has often received a great deal of attention from policy makers (U.S. Senate 196I). Recently questions concerning the competitive dynamics in the industry have resurfaced because of the renaissance in the generic drug industry (Scherer 1994). In particular, the puzzling rise in the prices of brand-name products subject to generic competition ran counter to simple explanations based on

${ }^{9}$ We tested the exogeneity of the brand-name price variable using a Hausman test and were unable to reject exogeneity of the variable.

${ }^{10}$ We recognize the possibility of endogeneity of brand name price from unique characteristics of markets for specific compounds that are observable to the firm but not the researcher. However, if these features are stable overtime the fixed effects model should control for these features. 
traditional conceptions of competition. These observations have led to a series of theoretical and empirical analyses of pricing in markets for pharmaceuticals. These analyses have reached different conclusions. In the work reported here we examined a sample of drugs with relatively large sales that have recently lost patent protection and faced competition from generics for the first time during the mid-1980s. Our data set represents the experience of drugs in a variety of: therapeutic categories (except antibiotics) and reflect drugs that lost patent during the time period where the Waxman-Hatch Act changed the rules governing generic entry.

Our econometric analysis leads us to several conclusions regarding price behavior in this market. First, it is clear that more competition among generic drug producers results in. substantial price reductions for those drugs. Second, increased competition from generics does not result in aggressive responses in price behavior by brand-name producers. We found no evidence of brand-name price reductions stemming from market entry by generic producers. In fact, the evidence we did uncover supports small price rises in response to expanded competition.

The substantial shift in market share from brand-name to generic producers $(40 \%-50 \%)$ along with the significantly reduced price of generic substitutes $(25 \%-30 \%$ lower) means that the average price of a prescription for a compound subject to generic competition has fallen.

One important limitation to our analysis should be noted. This study focused on competition at the level of the compound. That is, generics were assumed to compete with brand-name drugs and generic products that were the same chemical compound. 
Competition among drugs is more complicated than this. HMOs, managed care organizations and some physicians make choices among drugs within a therapeutic class. We have not accounted for therapeutic competition in this analysis. Future work on price dynamics in this industry should be expanded to take account of this more complicated set of competitive dynamics.

In sum, our results are consistent with notions of market segmentation on the demand side between classes of buyers with differing sensitivity to price. The absence of brand name price reductions due to generic competition, alongside large decreases in generic prices from intensified competition support this view. The implication of the empirical findings is that on balance the Waxman-Hatch Act had its intended effect of increasing price competition in the market for pharmaceutical products. The specific mechanisms through which price competition has taken place was, however, a surprise and is different from predictions based on simple versions of market models. 


\section{References:}

Berndt E.R., Griliches Z., and Rosett R.G., "On the Accuracy of Producer Price Indexes for Pharmaceutical Preparations: An Audit Based on Detailed Firm Specific Data" NBER Working Paper 3490 October 1990

Caves R.E., Whinston M.D., and Hurwitz M.A., "Patent Expiration, Entry and Competition in the U.S. Pharmaceutical Industry: An Exploratory Analysis" Brookings Papers on Economic Activity 1991

Comanor W.S. "The Political Economy of the Pharmaceutical Industry" Journal of Economic Literature September 1986

Frank R.G., and Salkever D.S., "Pricing Patent Loss and the Market for Pharmaceuticals" Southern Economic Journal October $1992^{\circ}$

Grabowski H. and Vernon J., "Brand Loyalty, Entry and Price Competition in Pharmaceuticals After the 1984 Drug Act" Journal of Law and Economics October, 1992

Office of Technology Assessment, Pharmaceutical R\&D Costs, Risks and Rewards U.S. G.P.O. 1993

Scherer F.M., "Pricing, Profits and Technological Progress in the Pharmaceutical Industry" Journal of Economic Perspectives Summer 1993

Scherer F.M. "The Pharmaceutical Industry" Unpublished Manuscript, Harvard University 1994

U.S. Senate, Subcommittee on Antitrust and Monopoly, Hearings on the Drug Industry 1961

Wiggins S.N., and Maness R., "Price Competition in Pharmaceutical Markets" Unpublished Manuscript, Department of Economics, Texas A\&M University, June 1994. 
Table 1. Variable Descriptions

\begin{tabular}{||l|l|c||}
\hline Variable & Definition & $\begin{array}{l}\text { Mean } \\
(\mathrm{SD})\end{array}$ \\
\hline NMFT & $\begin{array}{l}\text { Number of Generic Entrants } \\
\text { (Source: USP DI and orange } \\
\text { Book) }\end{array}$ & $\begin{array}{c}3.62 \\
(5.29)\end{array}$ \\
\hline Mkt Age & $\begin{array}{l}\text { Age of market in terms of } \\
\text { time the brand name product } \\
\text { was sold (Source: Paul } \\
\text { deHaen International) }\end{array}$ & $\begin{array}{l}13.78 \\
(7.73)\end{array}$ \\
\hline Yrs Off & $\begin{array}{l}\text { Year since the patent expired } \\
\text { (Source: FDA and telephone } \\
\text { Contact with originator firm) }\end{array}$ & $\begin{array}{c}1.35 \\
(2.01)\end{array}$ \\
\hline $\mathrm{P}_{\mathrm{G}}$ & $\begin{array}{l}\text { Average revenue per generic } \\
\text { extended unit (Source: IMS) }\end{array}$ & $\begin{array}{c}0.15 \\
(0.15)\end{array}$ \\
\hline $\mathrm{P}_{\mathrm{B}}$ & $\begin{array}{l}\text { Average revenue per brand } \\
\text { name extended unit (Source: } \\
\text { IMS) }\end{array}$ & $\begin{array}{c}0.29 \\
(0.21)\end{array}$ \\
\hline QPre & $\begin{array}{l}\text { Number of extended units sold } \\
\text { pre-patent loss }\end{array}$ & $\begin{array}{c}0.36 \times 10^{6} \\
\left(0.55 \times 10^{6}\right)\end{array}$ \\
\hline
\end{tabular}


Table 2. 1st Stage Entry Regressions Dependent Variable: NMFT ${ }^{1}$

\begin{tabular}{||l|c|c|c||}
\hline Variable & Fixed Effects & $\begin{array}{l}\text { Variance } \\
\text { Components }\end{array}$ & $\begin{array}{l}\text { Variance } \\
\text { Components }\end{array}$ \\
\hline QPre & - & $\begin{array}{c}0.53 \times 10^{-5} \\
(4.09)\end{array}$ & $\begin{array}{c}0.51 \times 10^{-5} \\
(4.05)\end{array}$ \\
\hline Mkt Age & - & $\begin{array}{c}0.020 \\
(0.20)\end{array}$ & $\begin{array}{c}0.026 \\
(0.27)\end{array}$ \\
\hline Yrs off & $\begin{array}{l}0.900 \\
5.13\end{array}$ & $\begin{array}{c}0.734 \\
(1.80)\end{array}$ & $\begin{array}{l}1.475 \\
(9.62)\end{array}$ \\
\hline Time & - & $\begin{array}{c}0.750 \\
(1.85)\end{array}$ & - \\
\hline Constant & $\begin{array}{l}4.588 \\
9.40\end{array}$ & $\begin{array}{c}-3.693 \\
(1.23)\end{array}$ & $\begin{array}{c}1.041 \\
(0.68)\end{array}$ \\
\hline N & 179 & 179 & 179 \\
\hline t statistic in parentheses & &
\end{tabular}


Table 3. Brand Name Price Regression ${ }^{2}$ (Dependent Variable: In $\mathrm{P}_{\mathrm{B}}$ )

\begin{tabular}{||l|c|c|c||}
\hline Variable & Fixed Effects & $\begin{array}{l}\text { TS Fixed } \\
\text { Effects }\end{array}$ & $\begin{array}{l}\text { TS Fixed } \\
\text { Effects }\end{array}$ \\
\hline NMFT & $\begin{array}{c}0.007 \\
(2.25)\end{array}$ & - & - \\
\hline NMFTHAT & - & - & - \\
\hline Constant & - & $\begin{array}{c}0.011 \\
(2.97)\end{array}$ & $\begin{array}{c}0.016 \\
(3.96)\end{array}$ \\
\hline$N$ & -1.487 \\
$(101.97)$ & $\begin{array}{c}-1.479 \\
(95.12)\end{array}$ & $\begin{array}{c}r 1.486 \\
(101.38)\end{array}$ \\
\hline
\end{tabular}

1 t statistics in parentheses

a lst stage fixed effects model

b Ist stage variance components with time trend 
Table 4. Generic Price Regressions ${ }^{1}$ (Dependent Variable: In $P_{G}$ )

\begin{tabular}{||l|l|l|l||}
\hline Variable & $\begin{array}{l}\text { TS Fixed } \\
\text { Effect }\end{array}$ & $\begin{array}{l}\text { TS Fixed } \\
\text { Effect }\end{array}$ & $\begin{array}{l}\text { TS Fixed } \\
\text { Effect }\end{array}$ \\
\hline NMFTHAT & $\begin{array}{l}-0.073^{\mathrm{a}} \\
(3.83)\end{array}$ & $\begin{array}{l}-0.097^{\mathrm{b}} \\
(2.58)\end{array}$ & $\begin{array}{c}-0.102^{\mathrm{c}} \\
(2.49)\end{array}$ \\
\hline In $\mathrm{P}_{\mathrm{B}}$ & $\begin{array}{l}0.074 \\
(0.41)\end{array}$ & $\begin{array}{l}0.089 \\
(0.30)\end{array}$ & $\begin{array}{c}0.082 \\
(0.02)\end{array}$ \\
\hline Constant & $\begin{array}{c}-1.480 \\
(5.06)\end{array}$ & $\begin{array}{c}-1.337 \\
(2.65)\end{array}$ & $\begin{array}{c}-1.510 \\
(2.97)\end{array}$ \\
\hline $\mathrm{N}$ & 154 & 154 & 154 \\
\hline
\end{tabular}

1 t statistics in parentheses

a lst stage fixed effects model

b lst stage variance components with time trend

c lst stage variance components with no time trend 